\title{
DEVELOPMENT OF AN ELECTRONIC CONTROL UNIT FOR FUEL INJECTION OF AN IC ENGINE
}

\author{
Gollapudi Arun Manohar ${ }^{1}$ \\ ${ }^{I}$ Assistant Professor, Mechanical Engineering Department, NEC, AP, India
}

\begin{abstract}
Injection of the fuel into the manifold of gasoline engines has become very common. Through the concept is not new, the advent of cost effective, compact and reliable electronic controls has a lot to do with the success of fuel injection in gasoline engines. Electronics has begun to play a key role in fuel management and ignition. The modern internal combustion has to meet extreme requirements of high power to weight ratio, low exhaust emission levels and high thermal efficiency. The precise control of the ignition timing, which is possible by electronic means, allows reliable combustion with low cycle by cycle variations. Such systems also allow the engine to run under conditions very close to knock onset so that maximum thermal efficiency can be realized. Electronic control of the injection system allows us to select correct air fuel ratio for different operating conditions. It reduces mal-distribution between cylinders and leads to extremely low levels of exhaust emissions. Stable idling can also be achieved through the use of electronic controls.
\end{abstract}

In this present work an ECU (Electronic Control Unit) hardware device is mainly developed for fuel injection control compatible with both 2-stroke and 4-stroke engines with PWM (Pulse Width Modulation) signal as input to the EFI (Electronic Fuel Injector). A slotted Optocoupler is used as the sensor for speed detection and producing the PWM signal. The EFI having solenoid controlled valve, which works on PWM signal to inject the fuel. 8051 microcontroller interfaced with the LCD to display the speed of the engine, has been used. The output PWM signals are tested with LabVIEW and the results are calibrated.

Keywords: ECU, Slotted Optocoupler, Fuel Injection Circuit, LabVIEW.

\section{INTRODUCTION}

Electronics gradually crept into the control devices handling fuel injection and spark ignition timing. Today there are no longer any systems featuring mechanical control. Since the electronics explosion in the automotive field, electronic solutions have proven to be reliable over time and have enabled to solve problems otherwise unsolvable. The electronics in today's vehicles have made the transition from simple components to complex semiconductor chips, incorporating in the process the interfacing capability of analog electronics, and proven reliability and flexibility of digital electronics. The content and complexity of electronics for circuit design, processing, power control sensing, signal conditioning and transient suppression are destined to increase even more in future vehicles.

An Electronic Control Unit (ECU) (also known as an "Engine Management System") is an electronic device, basically a computer, in an internal combustion engine that reads several sensors in the engine and uses the information to control the fuel injection and ignition systems of the engine. This approach allows an engine's operation to be controlled in great detail, allowing greater fuel efficiency, better power and responsiveness, and much lower pollution levels than earlier generations of engines. Because the ECU is dealing with actual measured engine performance from millisecond to millisecond, it can compensate for many variables that traditional systems cannot, such as ambient temperature, humidity, altitude (air density), fuel octane rating, as well as the demands made on it by the driver.
Modern ECUs use a microprocessor which can process the inputs from the engine sensors in real time. An electronic control unit contains the hardware and software (firmware). The hardware consists of electronic components on a printed circuit board (PCB). The main component on this circuit board is a micro-controller chip (CPU). The software is stored in the microcontroller or other chips on the PCB, typically in EPROMs or Flash-Memory so the CPU can be re-programmed by uploading updated code. This is also referred to as an (electronic) Engine Management System (EMS). Earlier ECU designs were based more on analogue computer circuitry, due to the fact that for analogue circuits processing speed is not an issue. It was not until around 1987 that digital electronics and embedded microprocessor systems became fast enough to process engine parameters in real time.

\section{SYSTEM MODEL}

The ECU consists of appropriate Integrated Circuits to obtain the required PWM signal for both two stroke and four stroke IC engine fuel injection system. A $16 \times 2$ LCD is interfaced with P89V51RD2FN microcontroller to display the type of stroke (2-Stroke or 4-Stroke) and the rotational speed of the crank shaft. Fig-2.1 shows the block diagram of the ECU including sensor, actuator and power supply. Details of each block are elaborated. 


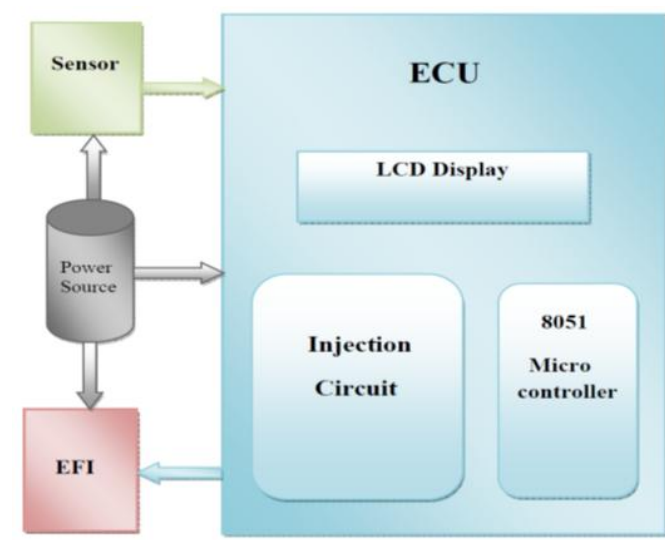

Fig-1: Block Diagram of ECU System

Sensors and data acquisition are very much important for measurement or feedback in Control. Actuators are used to regulate the process according to feedback from the sensors. In this project a Slotted Optocoupler is used as sensor for detecting the rotational speed of the crank shaft. A solenoid operated EFI is used as an actuator.

\subsection{Slotted Optocoupler}

There are many situations where signals and data need to be transferred from one subsystem to another within a piece of electronics equipment, or from one piece of equipment to another, without making a direct ohmic electrical connection. Often this is because the source and destination are at very different voltage levels. The ideal isolation scheme should only allow signal flow in one direction, should respond to DC levels, and should offer an extremely large resistance between the input and output circuits. These features are available in a class of optoelectronic devices called Optocouplers or Optoisolators.

Slotted Optocoupler is one of the types in Optocoupler, which is available with phototransistor and Darlington photodetectors, with the device package structured to provide an additional element of control.

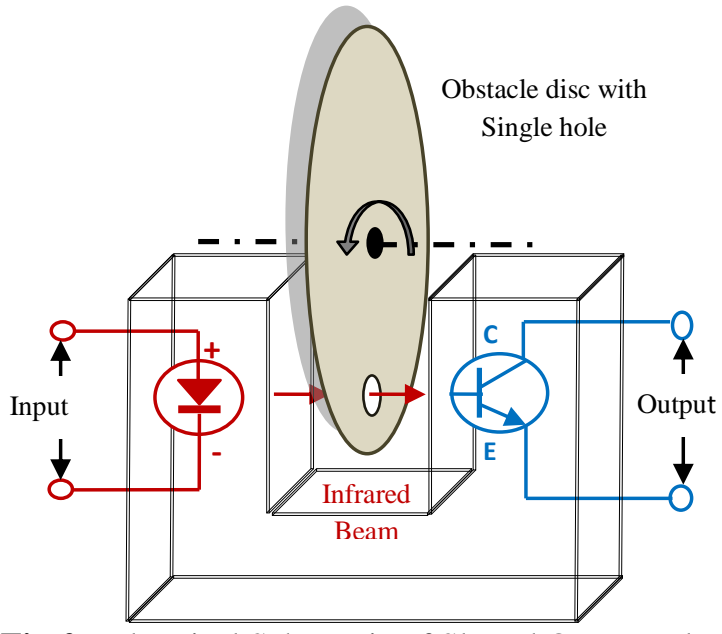

Fig-2: Electrical Schematic of Slotted Optocoupler In the present investigation the slotted Optocoupler is used to obtain rectangular pulse (Fig-3) as the obstacle which is a thin circular disk with single hole at the outer edge is rotating in the Optocoupler slot. When this thin plastic or metal disk connected to a crank shaft is rotated inside the slot of the Optocoupler, the beam will be detected by the phototransistor. So as the shaft rotates, it turns the circular disk, making and breaking the Infrared beam between the emitter and phototransistor, thereby generating rectangular pulses.
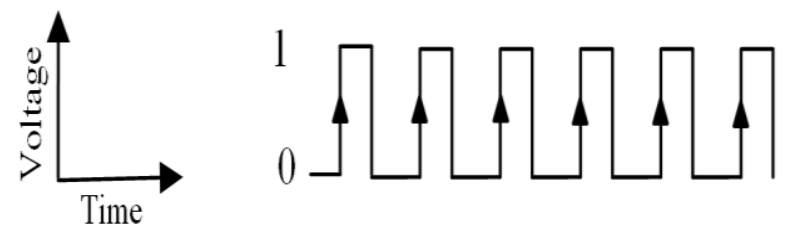

Fig-3: Rectangular Pulse

\subsection{Fuel Injection Circuit}

The actual Injection circuit which is shown in the Fig-4 is the major part of this project work. The output from the Slotted Optocoupler is given to Injection circuit.

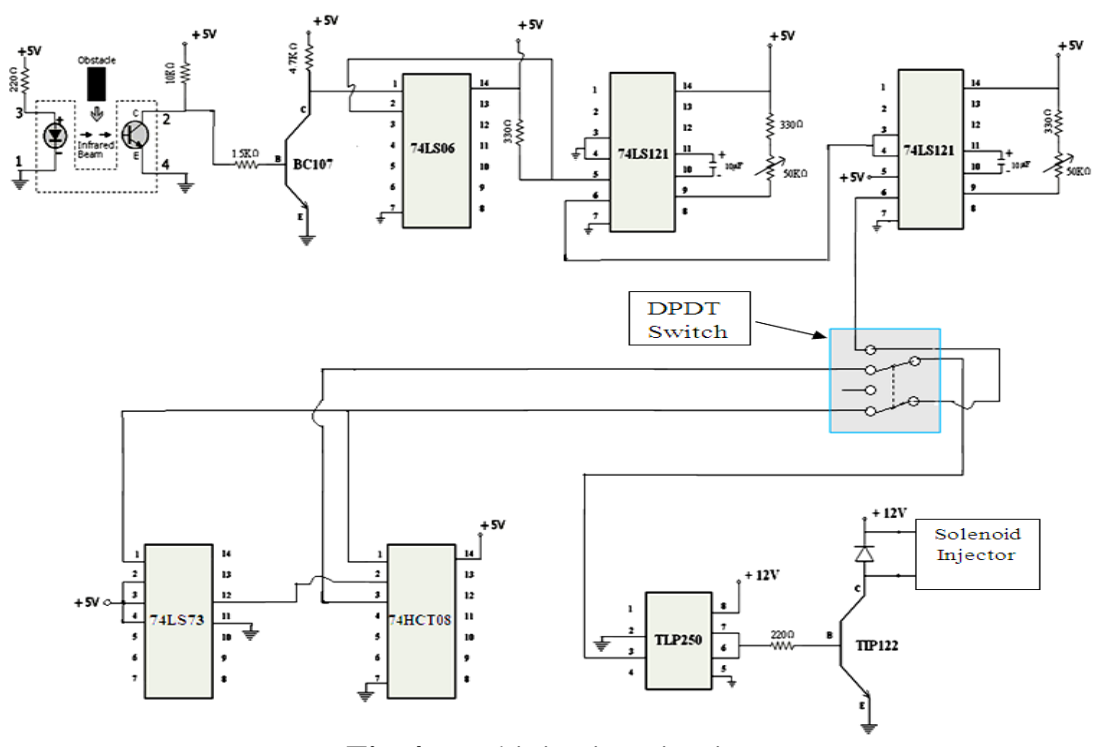

Fig-4: Fuel injection circuit 
The output signal from the Optocoupler which is in the form of pulses is given as input signal to this circuit. The sensor output is connected to the base of $\mathrm{BC} 107$ transistor through $1.5 \mathrm{k} \Omega$ resister to produce the required wave shaping and amplification of the signal. The amplified signal from $\mathrm{BC} 107$ collector pin is the input to the hex inverter buffer IC 70LS06. Hex inverter buffer/driver, features high-voltage open-collector to interface with high level circuits (such as MOS), or during high-current loads and also characterized for use as inverter buffer for driving TTL inputs. The inverting buffer is a single-input device which produces the state opposite the input. If the input is high, the output is low and vice versa, so the waveform which is given as input to the IC 74LS06 is inverted. The output from the inverter buffer is sent to the Monostable multivibrator IC, there by varying the resistance we can adjust the time of pulse that means the time period. The output from the Monostable multivibrator IC is connected to other Monostable multivibrator IC where the variation in the phase takes place by varying the resistance connected to it.

The output from the second Monostable multivibrator IC is connected to the DPDT switch as shown in the circuit. So, if the DPDT switch is triggered up connecting Monostable multivibrator output to TLP250 IC then the signal/waveform compatible for 2-stroke engine is obtained at the final output stage of the injection circuit. If the switch is triggered down connecting Monostable multivibrator output to TLP250 IC through J-K flip flop and AND gate IC's to generate the signal compatible for 4-stroke engine is obtained at the final output stage of the injection circuit. The TLP250 is an Optocoupler IC which provides optical isolation between the power circuit and the signal processing circuit. This helps in attenuating or even eliminating the bad effects of harmonics, created in the power amplifier stage, from reaching the signal processing stage.

\section{PROPOSED METHODOLOGY}

In general the two-stroke internal combustion engine completes one cycle of events for every revolution of the crankshaft i.e. for each and every revolution of the crank shaft fuel must be injected at a particular instant of time. In four-stroke internal combustion engine two revolutions of the crank shaft are required for the completion of one cycle. In this case fuel must be injected once for every two revolutions of the crank shaft.
To generate the required PWM signal compatible for 4Stroke internal combustion engine, the output from the second Monostable multivibrator IC signal is send through the J-K flip flop and AND gate IC. Where the AND gate works as a multiplier, it multiplies the output signals of second Monostable multivibrator IC and J-K flip flop.

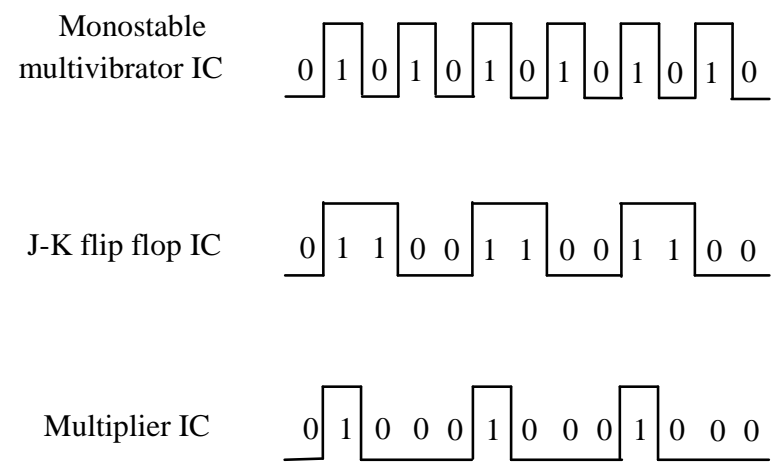

Fig-6: Output waveforms

As mentioned already, the time of the pulse is determined by an external resistor and capacitor connected to $\mathrm{R}_{\mathrm{EXT}}$, and $\mathrm{R}_{\mathrm{EXT}} / \mathrm{C}_{\mathrm{EXT}}$. The time of pulse is nothing but the opening time of the fuel injector, so by controlling the time of pulse we can control the real opening and closing time of the fuel injector. The pulse width is essentially determined by external timing components $\mathrm{R}_{\mathrm{EXT}}$ and $\mathrm{C}_{\mathrm{EXT}}$. As per the data sheet of SN74121 IC, time period or the output pulse width is defined by the relation $\mathrm{T}_{\mathrm{W}}=\mathrm{K} * \mathrm{R}_{\mathrm{EXT}} * \mathrm{C}_{\mathrm{EXT}}$. Where $\mathrm{R}_{\mathrm{EXT}}$ is in Kilo-ohm, $\mathrm{C}_{\mathrm{EXT}}$ is in pico Farad, $\mathrm{T}_{\mathrm{W}}$ is in nano second and $\mathrm{K}$ is a constant which is equal to 0.7 . In the present circuit $10 \mu \mathrm{F}$ capacitor and $0-50 \mathrm{~K} \Omega$ variable resister has been used, so according to these values.

Table-1: Theoretical values of output pulse width $\mathrm{T}_{\mathrm{W}}$ (in $\mathrm{ms}$ ) by varying the resistance value of the circuit

\begin{tabular}{|l|l|l|l|}
\hline S.No. & $\mathrm{R}_{\text {EXT }}$ & $\mathrm{C}_{\text {EXT }}$ & $\mathrm{T}_{\mathrm{W}}$ in $\mathrm{ms}$ \\
\hline 1 & $5 \mathrm{~K} \Omega$ & $10 \mu \mathrm{F}$ & 35 \\
\hline 2 & $10 \mathrm{~K} \Omega$ & $10 \mu \mathrm{F}$ & 70 \\
\hline 3 & $15 \mathrm{~K} \Omega$ & $10 \mu \mathrm{F}$ & 105 \\
\hline 4 & $20 \mathrm{~K} \Omega$ & $10 \mu \mathrm{F}$ & 140 \\
\hline 5 & $25 \mathrm{~K} \Omega$ & $10 \mu \mathrm{F}$ & 175 \\
\hline 6 & $30 \mathrm{~K} \Omega$ & $10 \mu \mathrm{F}$ & 210 \\
\hline 7 & $35 \mathrm{~K} \Omega$ & $10 \mu \mathrm{F}$ & 245 \\
\hline 8 & $40 \mathrm{~K} \Omega$ & $10 \mu \mathrm{F}$ & 280 \\
\hline
\end{tabular}

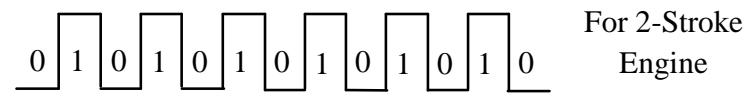

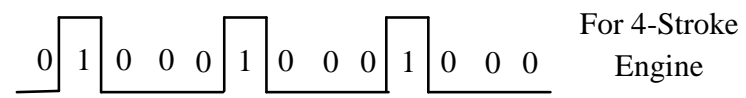

Fig-5: Required PWM Signal 


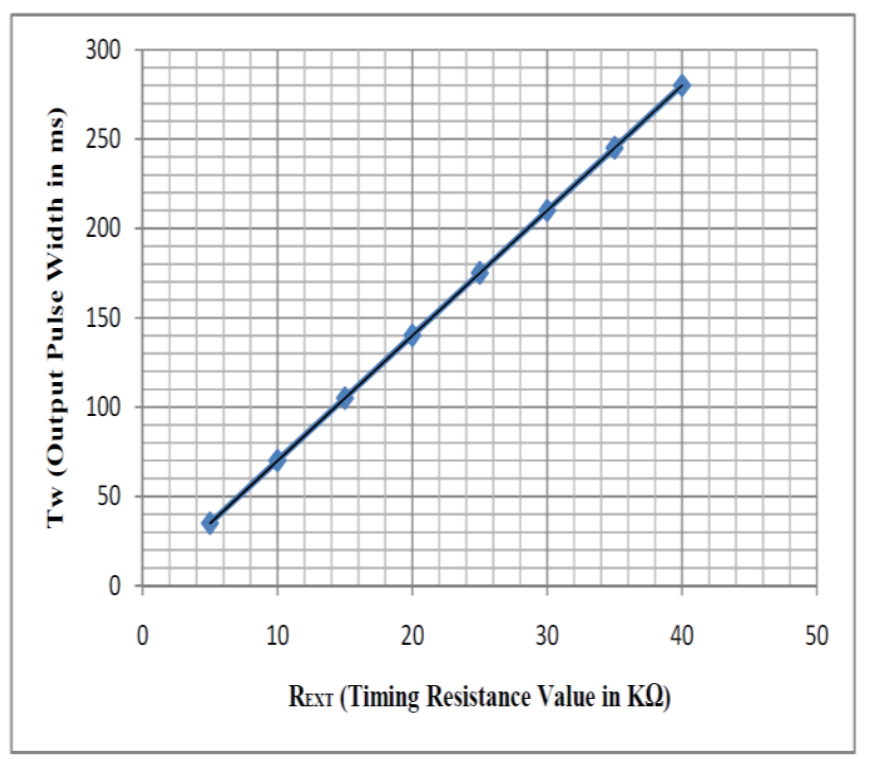

Fig-7: Time period of output pulse width vs. Resistance

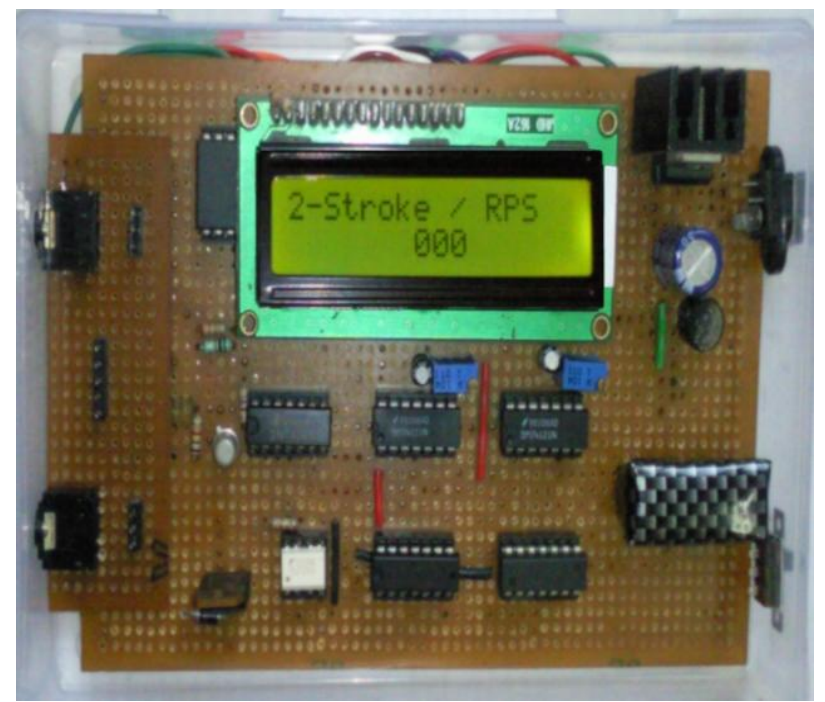

Fig-8: Developed ECU when DPDT switch is triggered up

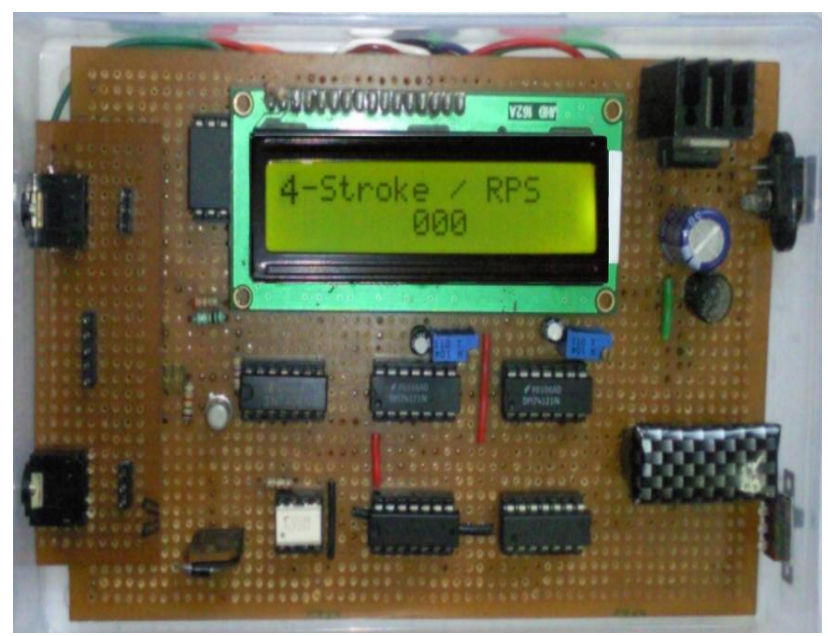

Fig-9: Developed ECU when DPDT switch is triggered down

\section{ECU TEST RESULTS}

ECU accepts the high speed pulses from the sensor as crankshaft rotates, which is already discussed in the working of the sensor. The results discussed below are the output waveform graphs obtained from the present designed ECU circuit at various points. These waveforms are appeared, analyzed and saved by LabVIEW. The hardware ECU is interfaced with the system software which was designed by LabVIEW. The software interface of hardware ECU is composed of data acquisition with waveform graphs. NI 9221 module was used for monitoring the output waveform graphs.

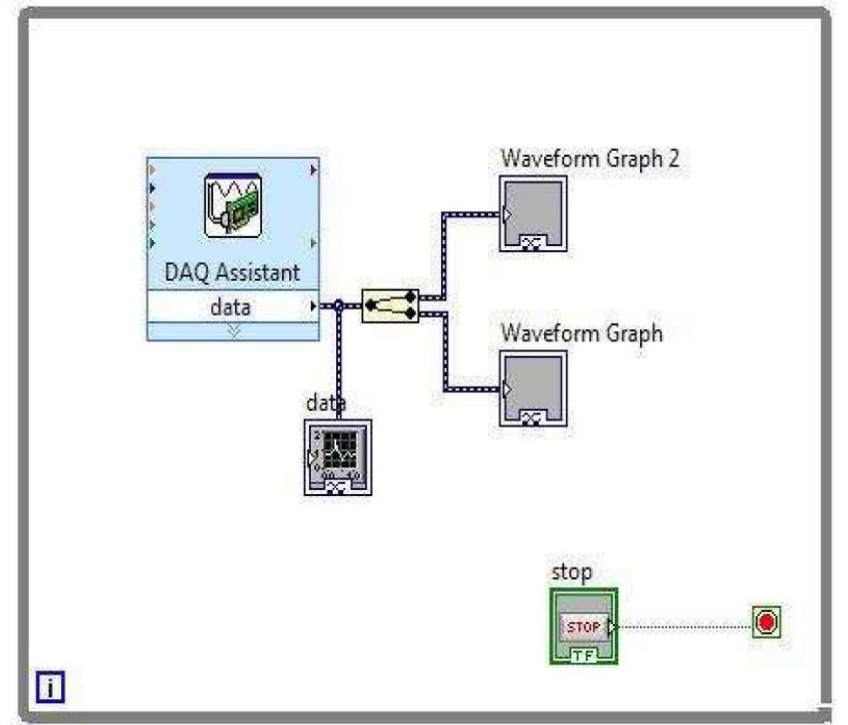

Fig-10: Software Interface Designed by LabVIEW

The waveforms are obtained by giving the input signal to the Slotted Optocoupler manually by an obstacle placed and removed alternatively at regular intervals of time, in between the emitter and phototransistor of the sensor, so that the waveform shape will be observed clearly by naked eye.

The waveform graphs are plotted by taking time duration of injection on $\mathrm{X}$-axis and voltage amplitude on Y-axis. Fig-11 shows the waveform graph of the slotted Optocoupler output with respect to ground.

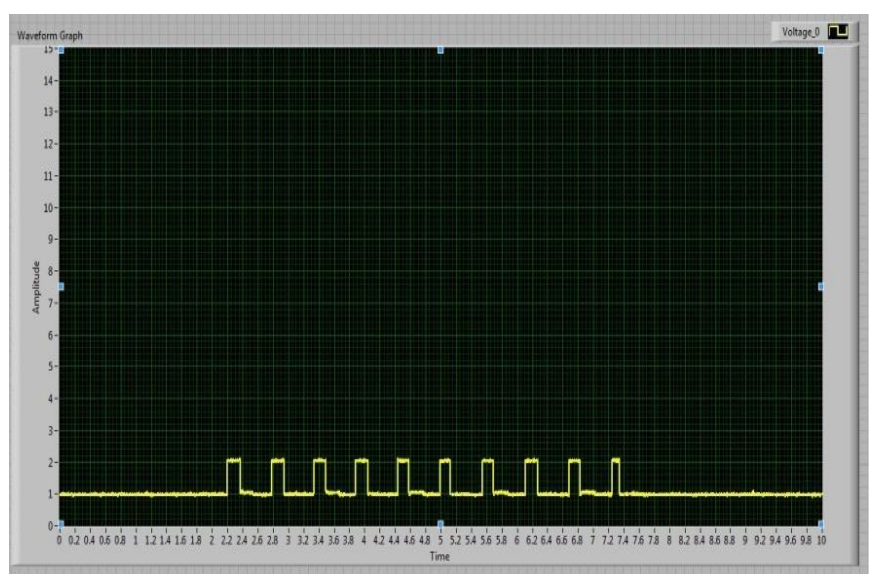

Fig-11: Sensor Output 


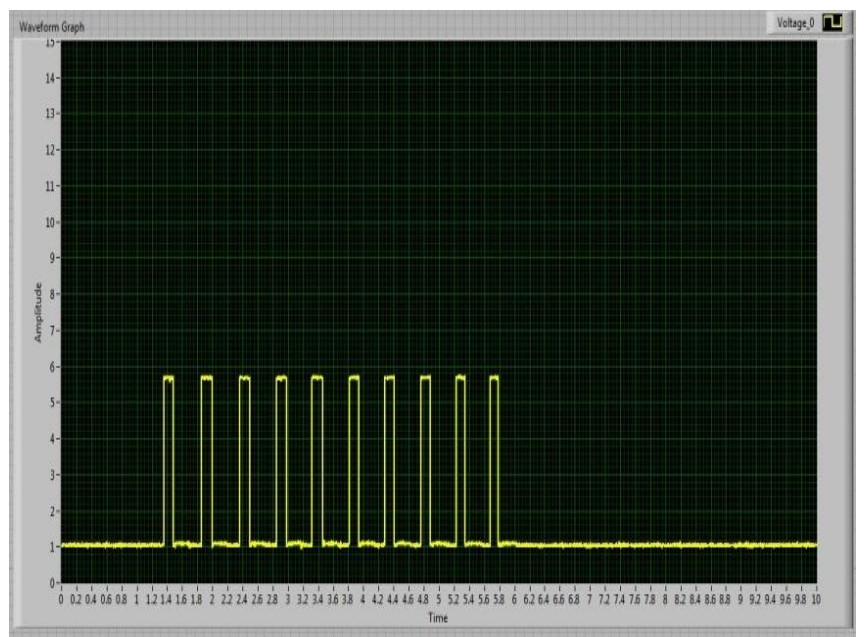

Fig-12: Output from Hex Inverter Buffer

To observe the variations in the time period by varying the resistance, the input waveform and the output waveform of Monostable multivibrator are combined in a single graph. The waveform graphs shown below are obtained by varying the resistance which is connected in between the pins 9 and 14 of Monostable multivibrator. These graphs are obtained at $10 \mathrm{~K} \Omega, 20 \mathrm{~K} \Omega, 30 \mathrm{~K} \Omega$ and $40 \mathrm{~K} \Omega$ respectively.

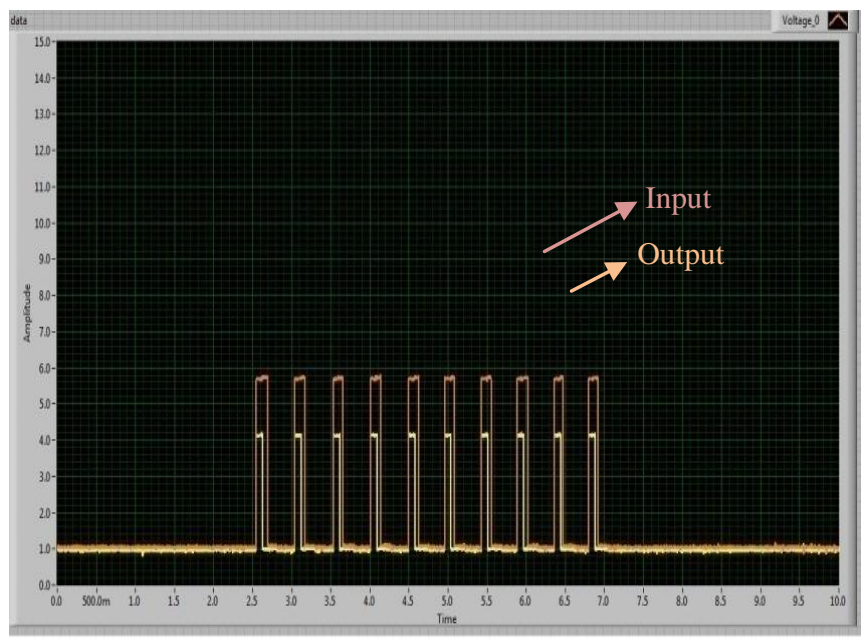

Fig-13: Input and Output waveform graph of Monostable multivibrator at $10 \mathrm{~K} \Omega$ resistance

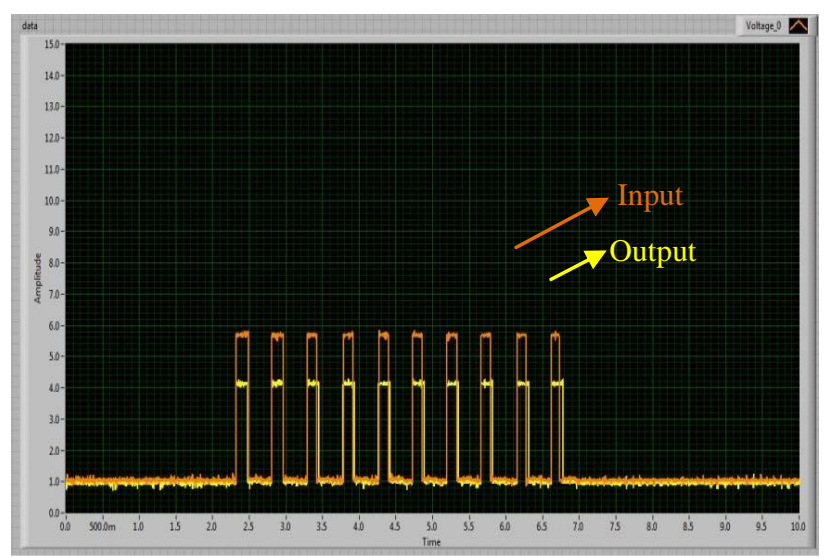

Fig-14: Input and Output waveform graph of Monostable multivibrator at $20 \mathrm{~K} \Omega$ resistance

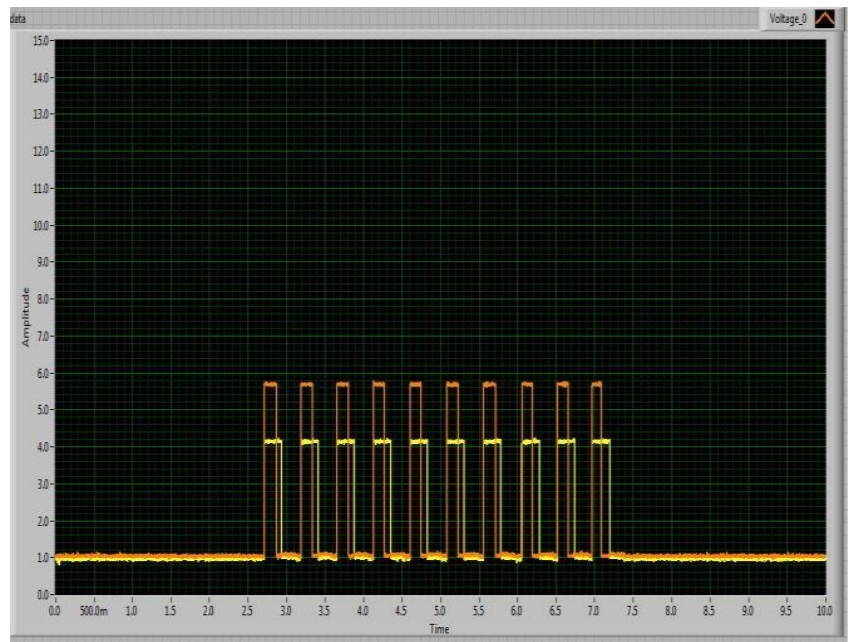

Fig-15: Input and Output waveform graph of Monostable multivibrator at $30 \mathrm{~K} \Omega$ resistance

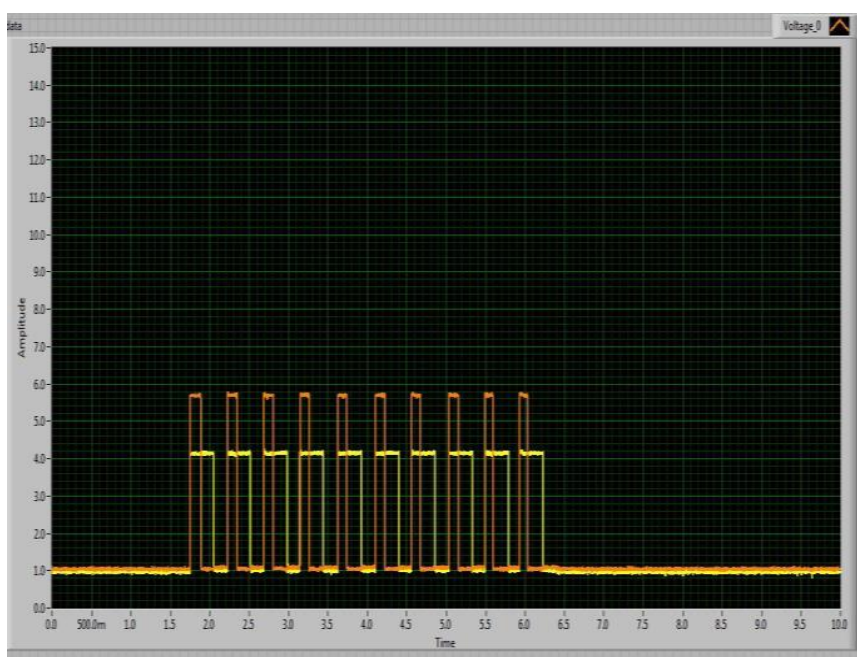

Fig-16: Input and Output waveform graph of Monostable multivibrator at $40 \mathrm{~K} \Omega$ resistance

By observing the waveform graphs (Fig-13, 14, 15 and 16) which are obtained by varying the resistance, the time period $\left(\mathrm{T}_{\mathrm{w}}\right)$ values are noted.

Table: 3 Time period values obtained from the waveforms

\begin{tabular}{|l|c|c|c|c|}
\hline \multicolumn{5}{|c|}{ Time period of the output pulse width $\left(\mathrm{T}_{\mathrm{w}}\right)$ in $\mathrm{ms}$} \\
\hline $\begin{array}{l}\mathbf{R}_{\text {EXT }} \\
\mathbf{C}_{\text {EXT }}\end{array}$ & $10 \mathrm{~K} \Omega$ & $20 \mathrm{~K} \Omega$ & $30 \mathrm{~K} \Omega$ & $40 \mathrm{~K} \Omega$ \\
\hline $10 \mu \mathrm{F}$ & 69.4 & 139.2 & 210 & 279.6 \\
\hline
\end{tabular}




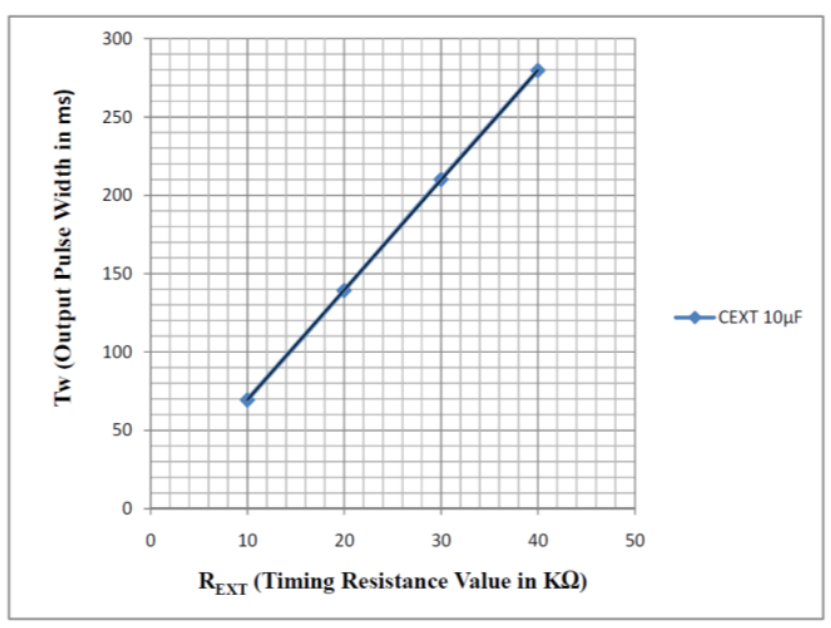

Fig-17: Time Period of output pulse width vs. Resistance values obtained from the Waveforms

Table: 4 Comparison between theoretical results and practical results, which are obtained from the waveforms

\begin{tabular}{|c|c|c|c|c|}
\hline \multicolumn{5}{|c|}{$\begin{array}{l}\text { Time period of the output pulse }\left(\mathrm{T}_{\mathrm{w}}\right) \text { in } \mathrm{ms} \text {, where } \mathrm{C}_{\mathrm{EXT}} \text { is } \\
\qquad 10 \mu \mathrm{F}\end{array}$} \\
\hline$\frac{\mathrm{R}_{\mathrm{EXT}}}{\mathrm{T}_{\mathrm{W}}}$ & $10 \mathrm{~K} \Omega$ & $20 \mathrm{~K} \Omega$ & $30 \mathrm{~K} \Omega$ & $40 \mathrm{~K} \Omega$ \\
\hline $\begin{array}{c}\text { From } \\
\text { Theoretical } \\
\text { Results }\end{array}$ & 70 & 140 & 210 & 280 \\
\hline $\begin{array}{c}\text { From } \\
\text { Waveform } \\
\text { Results }\end{array}$ & 69.4 & 139.2 & 210 & 279.6 \\
\hline
\end{tabular}

From Table: 4 we can observe that the time period of the output pulse width $\left(\mathrm{T}_{\mathrm{W}}\right)$ values from both Theoretical results and Practical results are nearly equal and the time period of output pulse width $\left(\mathrm{T}_{\mathrm{W}}\right)$ can be increased or decreased by varying the resistance value.

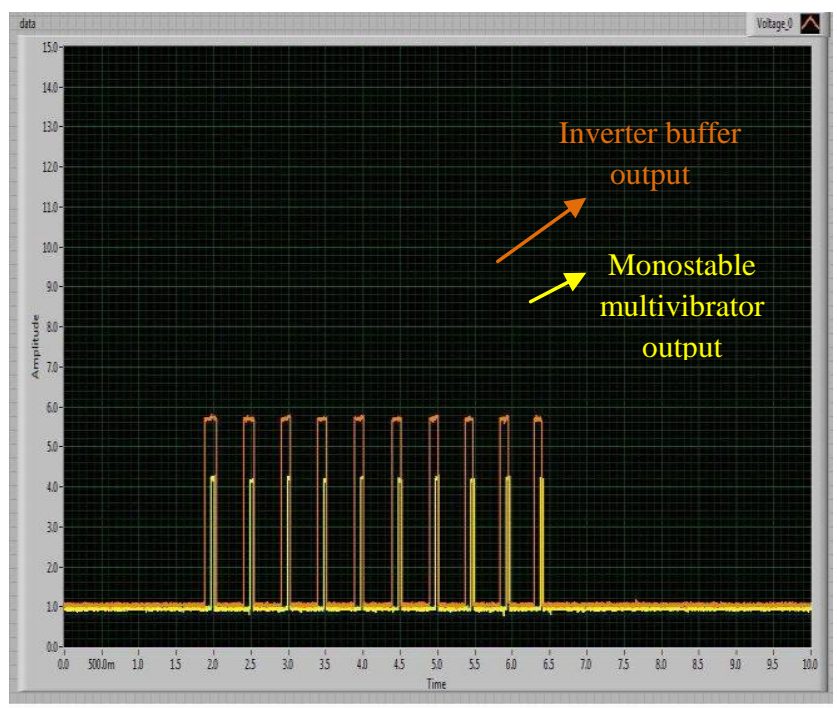

Fig-18: Combined waveform graph of Inverter buffer output and second Monostable multivibrator at $5 \mathrm{~K} \Omega$ resistance

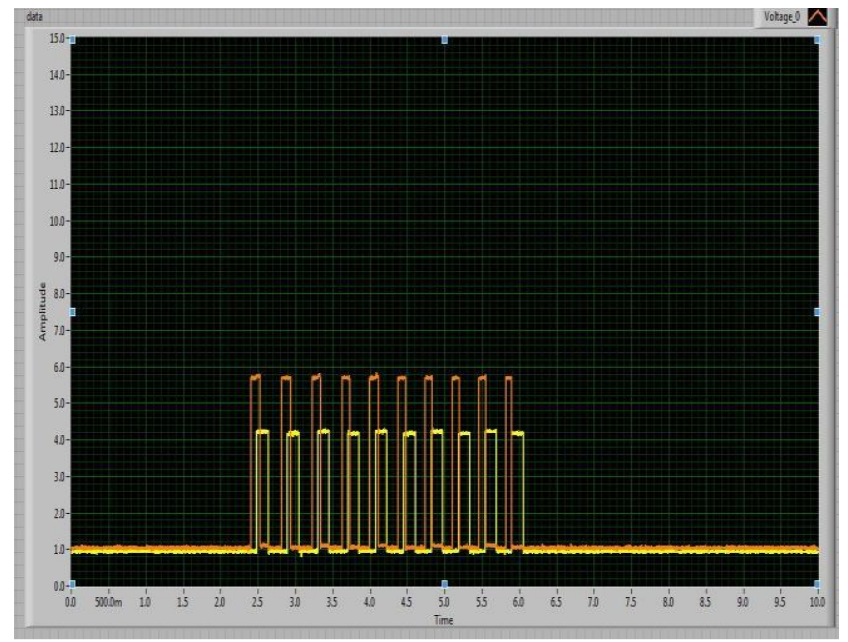

Fig-19: Combined waveform graph of Inverter buffer output and second Monostable multivibrator at $20 \mathrm{~K} \Omega$ resistance

So, by observing the above waveforms (Fig-18 and 19) we can observe the phase variation takes place by varying the resistance value.

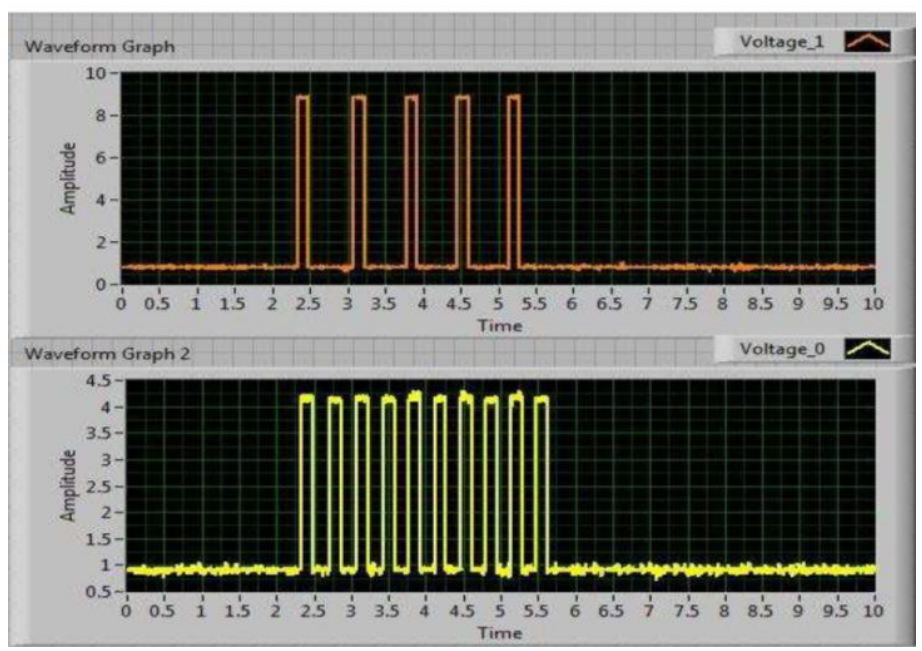

Fig-20: Waveforms which differs from 2-stroke (Bottom) \& 4-stroke (Top)

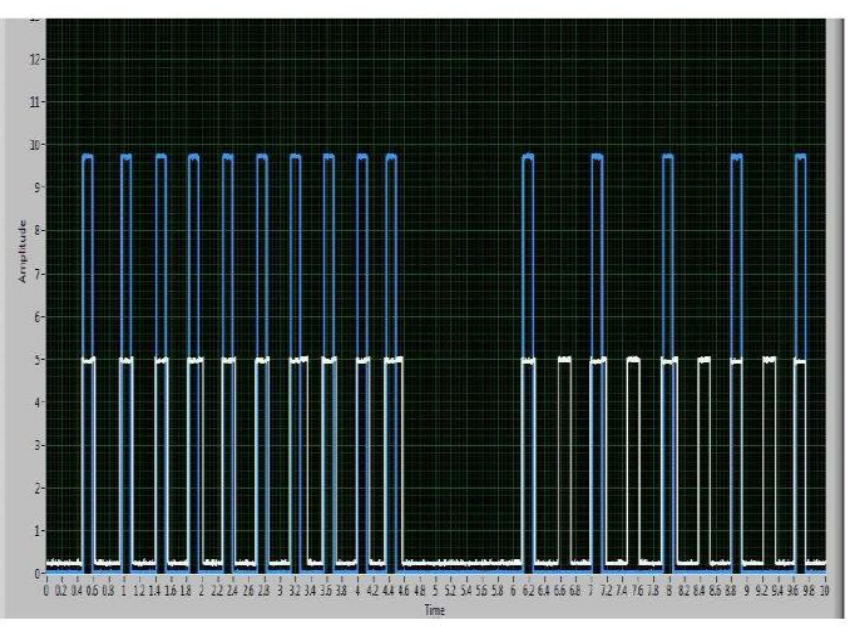

Fig-21: ECU outputs for 2-Stroke (Left) \& 4-Stroke (Right) with respect to input signal from the sensor 


\section{CONCLUSION}

In this paper the Electronic Control Unit (ECU) which is compatible for both 2-stroke and 4- stroke engine is designed, fabricated and the output waveforms are tested in the laboratory using LabVIEW. The slotted optocoupler is selected as the sensor for sensing the rotational speed of the crankshaft because it is a general purpose, having well output signal level and operates at $\sim 1$ to $20 \mathrm{~mA}$. Microcontroller (P89V51RD2FN) is interface with LCD (JHD 162A) to display the mode of operation (2-Stroke or 4-Stroke) of the ECU and RPS (Revolutions per Second) of the engine to which the ECU is prearranged. The obtained test results are carefully studied, analyzed and compared with the theoretical results and the following conclusions have been drawn.

- By varying the resistance of the first Monostable multivibrator, we can control the actual output pulse width of injection timing (in $\mathrm{ms}$ ) i.e. by increasing the resistance connected to the first Monostable multivibrator the output pulse width of PWM signal generated by ECU, is increased and vice versa.

- $\quad$ By varying the resistance connected to the second Monostable multivibrator, we can control the phase (Injection starting point) of the output signal.

- $\quad$ By triggering the DPDT switch ON and OFF we can obtain the output PWM signal from the ECU, which is compatible with 4-stroke engine and 2stroke engine.

\section{REFERENCES}

[1] Stefan Butzmann, Reinhard Buchhold (2004). "A new differential magnetoresistive gear wheel sensor with high suppression of external magnetic fields," Architecture. 16-19;

[2] L.M. Das, Rohit Gulati and P K Gupta, (2000). "Performance evaluation of a hydrogen-fuelled spark ignition engine using electronically controlled solenoidactuated injection system," International Journal of Hydrogen Energy 25: 569-579;

[3] "Gasoline-Engine Management", Professional Engineering publications, Robert Bosch.

[4] Toyota Motor Sales, U.S.A., (1983). "Engine controls input sensors": 1-34;

[5] William J. Fleming, (2001) "Overview of Automotive Sensors," IEEE, Sensors (Peterborough, NH) Vol. 1, no. 4: 296-308;

[6] Toyota Motor Sales, U.S.A. "Electronic Fuel Injection Overview" System: 1-9;

[7] R.A. Reed', P.W. Marshall, A.H. Johnston, J.L. Barth', C.J. Marshall, K.A.LaBel, M. D’Ordine, H.S. Kim6, M.A. Carts; (1998). "Emerging Optocoupler Issues with Energetic Particle-Induced Transients and Permanent Radiation Degradation" IEEE Transactions On Nuclear Science, Vol. 45, no. 6: 2833-2841;

[8] Mary D' Ordine, (1997). "Proton displacement damage," Measurement: 122-124;

[9] N. Saravanan and G. Nagarajan, (2010) "Performance and emission studies on port injection of hydrogen with varied flow rates with Diesel as an ignition source," Applied Energy 87, no. 7: 2218-2229,

[10] Cathleen Rooman, Daniël Coppée, and Maarten Kuijk, (2000). “Asynchronous 250-Mb/s Optical Receivers with Integrated Detector in Standard CMOS Technology for Optocoupler Applications," Esprit 35, no. 7: 953-958;

[11] Oliver Schatz, (2004). "Recent Trends in Automotive Sensors" Robert Bosch Gmbh, and Tuebinger Strasse, 236-239;

[12] G.Brasseur, (1997) "Robust Automotive Sensors," Technology Conference, Ottawa, Canad, (Peterborough, NH): 1278-1283;

[13] Wang Sujing, Wang Lide, Shen Ping, Liu Biao, Nie Xiaobo (2008). "Research on Electronically Controlled Fuel Injection System," Design (1849): 2-6;

[14] Todd L. Rachel, (1974). "Automotive Electronic Fuel Injection Essential Design Considerations -" Vol. VT-23, No. 2;

[15] E Vargil Vijay, Vargil Kumar E, Ch V Rama Rao, G N Swamy (2010) "Electronic Control Unit for an Adaptive Cruise Control System \& Engine Management System in a Vehicle using Electronic Fuel Injection," IEEE, Control: 143-146;

[16] David A Williams, (1995) “Optocoupler Selection For High Frequency Power Supply,” IEEE, Network: 9095.

[17] Wei-bin Wu, Tian-sheng HONG, Cai-ru LUO, Hailin WANG, Xue-jun YUE., (2010). "Hardware-in-loop of Alternative Fuel Engine ECU," Second International Conference on Computer Modeling and Simulation: 1013 ,

[18] Daniel Victor Camin abd Gianluigi Pessina, (2000) "Differential Optocoupler Amplifier with Low Noise, Low Power and Balanced Output", IEEE, Transactions On Nuclear Science, Vol. 47, no. 6: 2039-2044. William

[19] Dunn, (1990). "Automotive Sensor Application".

[20] Morgan MADEC, Jean-Baptiste KAMMERER, Luc HEBRARD, (2010). "Animproved compact model of cross-shaped horizontal CMOS-integrated Halleffect sensor" IEEE.

[21] Christopher O.Nwagboso (1996). "Automotive Sensory systems" Chapman \& Hall.

[22] Muhammad Ali Mazidi and Janice Gillispie Mazidi (2006). "The 8051 Microcontroller and Embedded Systems", Pearson Education.

[23] W.Bolton (2004). "Mechatronics", Pearson Education.

[24] Andrzej M. Pawlak (2006). "Sensors and Actuators in Mechatronics", Taylor \& Francis.

\section{BIOGRAPHY}

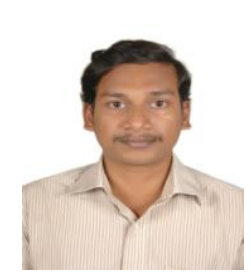

Arun Manohar received the B.Tech degree in mechanical engineering from Acharya Nagarjuna University, Guntur in 2008 and M.Tech degree in mechatronics engineering from NIT Karnataka, Surathkal in 2011. 